Ensino, Saúde e Ambiente-Vs (2), pp. 37 -49. Agosto, 2015

\title{
REFLEXÕES SOBRE O TRABALHO COM SEXUALIDADE NO ENSINO FUNDAMENTAL: DESAFIOS E POSSIBILIDADES
}

\section{REFLECTIONS ON WORKING WITH SEXUALITY IN BASIC EDUCATION: CHALLENGES AND POSSIBILITIES}

\author{
Kelly Mayara Poersch ${ }^{1}$, Bruna Caroline Kotz Kliemann ${ }^{1}$, Bárbara Grace Tobaldini de \\ Lima $^{2}$ \\ ${ }^{1}$ Universidade Estadual do Oeste do Paraná, kelly_poersch@ @otmail.com \\ ${ }^{1}$ Universidade Estadual do Oeste do Paraná, bruna.kli@ gmail.com \\ ${ }^{2}$ Universidade Federal da Fronteira Sul, barbara.lima@uffs.edu.br
}

\section{RESUMO}

O desenvolvimento humano é marcado por etapas, dentre elas, destaca-se a adolescência. Esta é caracterizada por mudanças fisiológicas, físicas e psicológicas, as quais influenciam direta ou indiretamente na vida do adolescente e de seus familiares. A sexualidade é a protagonista nessa fase do desenvolvimento e é mais notória em idade escolar, portanto, salienta-se a importância do tema sexualidade ser discutido com cautela na escola. Nesse contexto, o presente trabalho é um relato de experiência oriundo de uma atividade desenvolvida durante o estágio curricular supervisionado em Ciências, com alunos da educação básica e que teve como objetivo propiciar a eles uma reflexão sobre suas atitudes, comportamentos e valores, a fim de atenuar a visão negativa que a maioria deles tem em relação à sexualidade, reflexo da sociedade na qual estão inseridos e contribuir para que tomem decisões responsáveis a respeito da própria vida sexual. Os resultados demonstram que trabalhos realizados com pouca carga horária não são suficientes para que haja uma reflexão significativa das concepções dos alunos, evidenciando que o tema sexualidade deve ser abordado de forma contínua durante todo o processo de ensino e aprendizagem.

Palavras-chave: Adolescência, sexualidade, educação sexual, tabus, valores.

\begin{abstract}
The human development is marked by stages, among them, stands out the stage of adolescence. This is characterized by physiological, physical and psychological changes, which directly or indirectly influence the teenager's life and their families. Sexuality is the protagonist in this phase of development and is more noticeable in school age, therefore, we emphasize the importance of sexuality issue to be discussed with caution in school. In this context, the present work is an experience report that comes from an activity performed during the curricular internship supervised in Science, with basic education students and aimed to provide them a reflection about their attitudes, behaviors and values in order to mitigate the negative view that most of them have regarding sexuality, a reflection of the society in which they are inserted and to help them to take responsible decisions about their own sex life. The results show that work done with little hours are not enough for there to be a significant reflection in students' conceptions, showing that the theme sexuality must be addressed continuously throughout the process of teaching and learning.
\end{abstract}

Key words: Adolescence, sexuality, sexual education, taboo, values. 
Ensino, Saúde e Ambiente - Vs (2), pp. 37.49. Agosto, 2015

\section{INTRODUÇÃO}

A adolescência é uma fase do desenvolvimento humano marcada por conflitos em relação à sexualidade. Ocorrem transformações anatômicas, fisiológicas, psicológicas e sociais que levam o adolescente a estranhar seu próprio corpo e, consequentemente, a buscar pela sua identidade. Para isso, necessitam de contato físico e afetivo constantemente, além da busca incessante de respostas as suas dúvidas, as quais são sanadas por meio das informações fornecidas pelas mídias, pelos amigos, pela escola e em último caso pela família (BRÊTAS et al., 2011; ALBINO et al., 2005).

Muitas vezes as informações disponíveis na mídia são destituídas de reflexão e atropelam os valores e concepções morais levando os adolescentes a associar a sexualidade à genitalidade. As conversas entre amigos e pessoas da mesma faixa etária, que, portanto, estão vivendo os mesmos conflitos e contradições, acarretam em uma concepção distorcida de sexualidade. Os adolescentes, em muitos casos, não têm maturidade para discernir sobre as informações, pelo fato de muitos tabus e preconceitos ainda persistirem e dificultarem a tomada de decisão em relação à sexualidade (FOSSA, 2003).

Outros fatores que contribuem para a visão distorcida da sexualidade ocorrem no âmbito escolar e familiar. Nas escolas, ao trabalhar o tema sexualidade, os professores, por vezes, enfatizam somente os aspectos biológicos, enquanto que na família, os pais e filhos têm receio de conversar sobre o assunto. Durante muito tempo, conversas sobre sexualidade foram ignoradas nas escolas, pois temia-se que as discussões sobre o assunto servissem de estímulo para que os adolescentes iniciassem a vida sexual mais cedo. A escassez de informações era justificada pela importância de garantir a inocência por mais tempo (FOSSA, 2003).

Grizze, Santos e Oliveira (2010), afirmam que os adolescentes normalmente remetem a "sexualidade" a relação sexual heterossexual, gravidez, doenças sexualmente transmissíveis (DST’s), aspectos biológicos, entre outros, demonstrando uma carência de informações concretas e coerentes sobre a sexualidade.

É importante que a família e a escola trabalhem em conjunto visando desmistificar a sexualidade, visto que esse tema "[...] ainda encontra-se cercado de mistério e tabus [...]" (SOUSA; FERNANDES; BARROZO, 2006, p. 409). Assim, possibilita aos alunos compreenderem que a sexualidade vai além do corpo e dos aspectos reprodutivos e está relacionada com crenças, ideologias e imaginações, sendo 
indispensável para o desenvolvimento da personalidade do indivíduo (BRÊTAS et al., 2011; ALBINO et al., 2005).

Falar sobre sexualidade é falar de nossa história, nossas emoções, nossas relações com as outras pessoas, nossos costumes e nossos desejos. É uma forma de expressão, comunicação e afeto que se manifesta a todo o momento, seja por meio de um gesto, de um olhar ou de uma ação. É a energia que nos motiva a encontrar o amor, o contato e a intimidade e que se constrói passo a passo, a partir do momento em que nascemos (BRASIL, 2012, p. 13).

Como descrito acima, é importante que pais e professores trabalhem a sexualidade com seus filhos e alunos. Porém, essa não é uma tarefa fácil, pois as crianças, adolescentes e jovens estão inseridos em uma sociedade que remete a sexualidade a algo proibido, promíscuo e imoral e com isso podem crescer com uma formação cultural que dificulta a conversa sobre o assunto.

Sobre os professores em âmbito escolar, é necessário que haja uma formação sobre sexualidade para que, em seguida, esse possa conversar com seus alunos sobre o assunto. Um ponto importante é que as opiniões pessoais do professor não devem influenciar na formação dos alunos, mas sim, proporcionar momentos de reflexão acerca dos assuntos, envolvendo valores, relações interpessoais, questões biológicas e fisiológicas, relações sexuais, entre outros, afim de que os alunos possam construir uma opinião sobre esses e outros temas. Marquini (2007, p.02) salienta que "[...] as atividades desenvolvidas no ambiente escolar, devem contemplar a auto-estima pessoal e das relações interpessoais, envolvendo as diferenças e escolhas sobre a sexualidade $[\ldots] "$.

Outros autores (ALBINO et al., 2005; FIGUEIRÓ, 2009; BRÊTAS et al., 2011) sugerem que seja trabalhado com os alunos o conhecimento científico com informações claras sobre o assunto e não apenas os aspectos biológicos, reprodutivos e as DST's, pois essa ênfase não permite ao adolescente entender a sexualidade e definir uma postura diante dela.

Os adolescentes constroem seus conhecimentos em relação à sexualidade vinculados às práticas sociais vivenciadas na família, na comunidade e na escola, por isso, é importante que esse espaço identifique o que eles sabem em relação à sexualidade e o que os mesmos têm interesse em aprender, contribuindo assim para a formação destes sujeitos como cidadãos críticos e reflexivos (FOSSA, 2003).

Outro fator importante, é que o professor compreenda a diferença entre os conceitos: sexualidade, orientação sexual e educação sexual. A sexualidade inclui o sexo, intimidade, sentimentos, valores e a comunicação, fatores que vão além do corpo 
e dos órgãos genitais. A orientação sexual oferta informações a fim de proporcionar reflexões e questionamentos acerca dos assuntos que rondam a sexualidade como: crenças, tabus e valores. Já a educação sexual, envolve todas as formas de aprendizagem sobre a sexualidade: família, escola, religião, livros, internet, amigos, mídia, entre outros (FIGUEIRÓ, 2006; GTPOS, 1994 apud PARANÁ-SEED, 2009).

Diante do exposto e do fato do tema sexualidade estar presente nos Parâmetros Curriculares Nacionais (PCNs), a escola pode orientar discussões sobre sexualidade, para que o adolescente possa compreender melhor o momento que está vivendo, de modo que passe a tratar este assunto com mais seriedade, responsabilidade e compromisso (AMORIM; MAIA, 2012).

Dessa forma, o referido trabalho é um relato de experiência proveniente de uma atividade desenvolvida com os alunos da educação básica e que teve como objetivo propiciar a eles uma reflexão sobre suas atitudes, comportamentos e valores, a fim de atenuar a visão negativa que a maioria deles tem em relação à sexualidade, reflexo da sociedade na qual estão inseridos e contribuir para que tomem decisões responsáveis a respeito da própria vida sexual.

\section{ASPECTOS DE ORDEM METODOLÓGICA}

O presente trabalho é oriundo de uma atividade relacionada ao estágio curricular supervisionado no ensino de Ciências, que além da regência (com 14horasaula) também contempla uma ação didática, na forma de um projeto. Nesse sentido, desenvolveu-se um projeto a partir da temática sexualidade para 33 alunos de um oitavo ano de um colégio estadual da região oeste do Paraná, com duração de 4horas-aula, divididas em dois encontros. As atividades foram organizadas a partir da metodologia expositiva e dialogada apresentada por Morais (2009), pois permite a participação dos alunos ao invés de o professor ser o ponto central da aula. Além disso, foram propostas diferentes dinâmicas e discussões acerca do assunto, divididos em dois momentos: Primeiro momento: 1) Jogo da batata quente e 2) roda de conversa; segundo momento: 3) vídeo "adolescência e sexualidade " "que aborda a puberdade e 4) produção textual.

Para o jogo da batata quente os alunos foram orientados, inicialmente, a formarem um círculo. Em seguida foi entregue um balão para ser passado de mão em mão enquanto uma música tocava. Ao parar a música o aluno que estava com o balão na

${ }^{1} O$ vídeo utilizado pode ser acessado em: https://www.youtube.com/watch?v=NNQdhzfNbTI. 
mão falava a primeira palavra que vinha a mente sobre sexualidade. Depois que todos os alunos falaram ao menos uma palavra, iniciou-se uma roda de conversa, onde os professores direcionaram a discussão, a partir dos conceitos relatados durante a atividade da batata quente, com o intuito de proporcionar uma reflexão inicial sobre a temática. As atividades iniciais tiveram como objetivo analisar o conhecimento prévio dos alunos sobre o assunto sexualidade.

Após a roda de conversa sentiu-se a necessidade de mostrar um vídeo abordando o tema puberdade, devido à inquietação por parte dos alunos sobre esse tema, na primeira atividade. Como atividade de encerramento, foi proposto aos alunos a produção de um texto, em que o tema central seria um dos aspectos relacionados à sexualidade, tais como: puberdade, relação sexual, valores éticos, bullying, higiene, respeito, entre outros, e que foi trabalhado em sala de aula.

O material oriundo da produção textual foi analisado com objetivo de observar como os alunos compreenderam a temática trabalhada, bem como, se os mesmos foram estimulados a refletir sobre suas ações, valores, julgamentos e outros aspectos relacionados à sexualidade.

A partir do desenvolvimento dessas atividades, selecionamos as anotações ${ }^{2}$ realizadas pelas professoras a partir da atividade da batata quente, bem como a análise dos textos oriundos da produção textual, para elaborar este trabalho. Ainda que 33 alunos tenham participado das atividades, foram selecionados 17 deles, pois apenas esses alunos participaram das quatro atividades. Estes são identificados a partir de códigos formados pela letra "A" (Alunos) seguida por uma sequência numérica de 01 a 17, por exemplo, A1.

\section{ANÁLISE DAS ATIVIDADES DESENVOLVIDAS}

$\mathrm{Na}$ atividade inicial, o jogo da batata quente, os alunos foram orientados a falar a primeira palavra ou expressão que viesse a mente relacionada à sexualidade e na análise dos registros verificou-se que as mais citadas por eles foram: AIDS, camisinha, pênis, xana, gravidez, orgasmo, DST, pepeca, piroca, HPV, sexo, penetração, espermatozoide, prazer, gozo, virgindade, anal, óvulo, escroto, espanhola, sexo oral, beijo, seios, demonstrando que a visão da sexualidade relacionada ao ato sexual ou órgãos genitais

\footnotetext{
${ }^{2}$ As anotações, derivadas da atividade da batata quente, referem-se às palavras que foram citadas pelos alunos no momento que a música parava de tocar.
} 
ainda é muito presente entre os adolescentes. Entretanto, também foram abordadas expressões, como: carinho, amor, dignidade, sinceridade, amizade, respeito, fidelidade, casamento, namoro, que relacionam o tema sexualidade a valores, comportamentos e atitudes, porém essas foram menos citadas.

As palavras e expressões identificadas na atividade inicial corroboram com o trabalho realizado por Grizze, Santos e Oliveira (2010) os quais citam que os adolescentes geralmente associam sexualidade a relação sexual, e aspectos negativos como as DST's bem como, com o trabalho de Fossa (2003, p.36) que afirma que "[...] com frequência, a sexualidade é apresentada e resumida a sexo e genitalidade".

Inferimos a partir das palavras e expressões citadas pelos alunos, que o trabalho sobre sexualidade no ambiente escolar pode estar relacionado apenas aos conceitos biológicos e reprodutivos e/ou, que há privação do diálogo entre os familiares. Ambas as atitudes podem culminar na busca por outros meios ou estratégias para sanar as dúvidas, como nos meios de comunicação, os quais vinculam informações com apelo sexual, ou em conversas com os amigos, reproduzindo apenas o que ouvem sem saber o real significado.

Para alguns autores (GOMES et al., 2002; GRIZZE; SANTOS; OLIVEIRA, 2010; RODRIGUEZ 2010), as informações disseminadas entre os jovens geralmente dizem respeito à DST's e preservativos, no entanto, assuntos que envolvam as mudanças no corpo, a puberdade e os conflitos psicológicos relacionados ao crescimento, são raramente discutidos. Segundo Cano, Ferriani e Gomes (2000), a vulgarização e banalização da sexualidade dificultam o ato de educar e de relacionar o sexo à afetividade, responsabilidade e cuidado com a própria saúde.

A segunda atividade, a roda de conversa, foi realizada a partir das palavras e expressões citadas pelos alunos durante o jogo inicial, com objetivo de discutir a temática sexualidade com os participantes. Assim, foram realizados diferentes questionamentos. Um deles foi em relação à diferença de tratamento entre os diferentes gêneros. A1 e A7 se manifestaram a partir das seguintes falas:

A1:“Tipo, o pia $^{3}$ o quanto antes namorar é melhor, mas as meninas tem que ser mais tarde o possível. [...] Menino tem fama de pegador;"

A7: "Se a mulher pega um monte de gente ela é piranha."

\footnotetext{
${ }^{3}$ Forma de tratamento para uma criança do sexo masculino, frequentemente, utilizada na região Sul do Brasil.
} 
As falas citadas remetem a diferença da educação cultural entre os gêneros, sendo essa oriunda desde a época da colonização, onde a mulher era vista como frágil, submissa e responsável por cuidar da casa e dos filhos, sem poder de voz perante o marido, enquanto este mantinha relações extra-matrimôniais (SOUZA; BALDWIN; ROSA, 2000). Cano et. al, (1999, p. 01) complementam ao afirmar que "[...] o tabu que pesa sobre a iniciativa sexual da mulher tem muito a ver com o papel de subordinação ao homem". As mulheres apresentam um contexto histórico de repressão, passividade e diferenciação de condutas em relação aos homens (SILVA, et al, 2014). Sobre as falas dos alunos A1 e A7, foi possível explicar que eles devem levar em consideração que muitos pais cresceram em uma família patriarcal onde as mulheres eram frágeis, passivas e subordinadas ao homem e a consequência foi a transmissão dessa cultura aos filhos.

Outro fator explorado foi em relação à virgindade, em que A19 e A7 falam respectivamente: "É uma coisa natural”, "Todo mundo tem a hora especial para perder". Já na fala de A18 percebe-se o receio em assumir a virgindade perante os amigos, como evidenciado a seguir: "Ah, mas se a gente fala que é virgem todo mundo tira sarro". A cobrança presente na vida dos adolescentes referentes à perda e/ou a omissão da virgindade, pode estar relacionada com os programas veiculados pelas diferentes mídias bem como, a necessidade de fazer parte de um grupo e agir como os demais colegas. Muitos sentem-se pressionados a iniciar a vida sexual porque os amigos já iniciaram e por isso ficam envergonhados e intimidados em assumir a virgindade perante o grupo (TAQUETTE; VILHENA, 2008; PRADO; PAES; FÍRBIDA, 2013).

Nessa situação os alunos foram orientados para que não se sintam intimidados ou com vergonha por serem virgens, afinal, a primeira relação sexual deve acontecer somente quando a pessoa sentir-se preparada, nos aspectos afetivos, emocionais, biológicos, entre outros, para tomar essa decisão. Ter relação sexual por medo de ser alvo de brincadeira dos amigos pode levar a futuras frustrações, então, o ideal é pensar bem antes de qualquer ação. Além disso, os alunos foram aconselhados no sentido de que as pessoas não têm o direito de julgar o outro e que o bullying em relação à virgindade é algo que deve ser evitado.

Após o desenvolvimento dessas atividades, foi proposta aos alunos a produção de uma história sobre sexualidade. As temáticas presentes nas produções foram: 1) tabus e regras morais; 2) puberdade; 3) ato sexual; 4) uso das drogas. Em seis das produções textuais constatou-se a presença de tabus e regras morais, que segundo 
Cardoso, Lazzarotto e $\operatorname{Braz}$ (p.27, 2005), foram “[...] impostos pelas religiões, pela sociedade, influenciando as estruturas familiares e os atos das pessoas" ao longo dos anos. Alguns trechos das produções dos alunos, que demonstram tais aspectos, estão transcritos a seguir:

A3 “[...] seus pais não conversavam sobre sexualidade com ela, e diziam que isso não era coisa para ser discutida";

A5 "[...] os homens tem que começar a namorar mais cedo e as mulheres tem que [...] ficar atrás do "fugão" porque o homem tem que mostrar pro pai que ele não é viado"(sic);

A12 “[...] Por que se eu ficar com alguém meu pai me mata[...]";

A14 "O pia tem mais liberdade do que as meninas [...]";

A15 "[...] caso a mulher engravidar; na maioria das vezes ela tem que sair de casa com medo do pai $[\ldots] "$.

Um aspecto que pode ter influenciado na opinião "machista" implícita nos trechos, é o fato de que o sexo era julgado como algo imoral e pecaminoso (CARDOSO, et al, 2005).

Outro grupo apresentou elementos diferentes para a sexualidade. Os alunos A2, A6, A7 e A17 relacionaram a sexualidade com valores, respeito, carinho, amor e diálogo, como destacado a seguir:

A6: "Na sexualidade existe respeito, carinho e amor [...] a sexualidade tem que ter respeito, pois isso aconteceu ou acontecerá com todos"

A17 "Quando os adolecentes estão na puberdade os pais também precisam estar presentes conversar com seus filhos explicar, por que eles também já pasaram por isso. [...] (sic)".

Já os alunos A4, A8, A9, A12, A15 e A16 destacaram principalmente algumas atitudes relacionadas com ações disseminadas em âmbito social e que em alguns casos estão relacionadas com elementos de ordem preconceituosa. Demonstraram também uma reflexão sobre discussões corriqueiras entre os jovens. Esses elementos podem ser observados a partir de A9, ao escrever que "[...] Muitos homens não preferem se relacionar com pessoas "gordas" [...] a camisinha, muitos não gostam de usar, falam que é melhor sem, até concordo, mas ela não foi feita atoa [...]”.

Estes trechos estão relacionados com os objetivos da educação sexual, que é “[...] fornecer informações sobre a sexualidade e organizar um espaço de reflexões e questionamentos sobre posturas, tabus, crenças e valores a respeito de relacionamentos e comportamentos sexuais [...]"(GTPOS, 1994, p.08 apud PARANÁ-SEED, 2009, p.42). Salientamos que A6 descreveu a sexualidade como algo que tem que existir respeito, carinho e amor, do mesmo modo que Figueiró (2006, p.02) conceituou que a sexualidade "[...] inclui o sexo, a afetividade, o carinho, o prazer, o amor [...]". 
Além disso, outros assuntos estiveram presentes nos textos, como a puberdade, que foi conceituada da seguinte maneira:

A1 "[...] nem eu estou me entendendo [...] na TPM ninguém me aguenta [...] as meninas passam pela puberdade mais cedo[...]. Então isso é só uma fase de transformação do nosso corpo, um período onde deixamos de ser crianças e passamos para a fase adulta".

A4 "[...] a puberdade é aquilo em que o corpo evolui [...]".

A6 “[...] As mudanças ocorrem na puberdade tanto nos meninos, tanto nas meninas. Nas meninas: aumento dos seios, quadris e nascem pelos. [...] Nos meninos as mudanças são: crescimento dos ombros, pêlos, mudança de voz, altura e pomo de adão".

A11 "É quando o corpo de um adolecente muda [...] não tome atitudes quando seus "ormonios" ficarem agitados (sic)".

As falas dos alunos(as) corroboram com Fossa (2003) quando diz que as alterações corporais marcam a transição da infância para a adolescência. Segundo Davim et al. (2009) as alterações incluem maturação sexual, mudanças físicas e estéticas, eclosão hormonal, desenvolvimento de caracteres sexuais secundários, entre outros. As mudanças físicas aliadas às mudanças psicológicas e comportamentais dos adolescentes levam a mudar a forma de se relacionar com o mundo, mas principalmente, com os pais, pois podem resultar em crises de rebeldia, impaciência e por vezes até agressividade (CANO; FERRIANI; GOMES, 2000; PRADO; PAES; FÍRBIDA, 2013).

Outra constatação, derivada das produções textuais, foi recorrente ao ato sexual e gravidez:

A04 "[...] essas pessoas podem fazer sexo sem proteção e depois se arrepender pegando vírus e até a gravidez indesejada".

A08 "[...] tem uma relação sexual, as mulheres engravidam e tem filhos."

A10 "[...] Na primeira vez que ela "vez" sexo com ele ela engravidou [...]."

A13 “[...] Mãe o que é sexualidade? É a mesma coisa que ato sexual [...]."

Percebemos a partir dessas falas que quatro alunos associaram a primeira relação sexual (ato sexual) à gravidez, corroborando com o exposto por Prado, Paes e Fírbida (2013) que expõem em seus trabalhos que a gravidez está muito relacionada com o início da vida sexual precoce e ao fato de que os adolescentes muitas vezes são influenciáveis, deixando de refletir sobre as consequências futuras de determinados atos. Ademais, muitos adolescentes não planejam a primeira relação sexual, relatando que ela simplesmente acontece e a prática contraceptiva acaba sendo esquecida (BORGES; SCHOR, 2005).

Três alunos relacionaram, em suas produções, o uso das drogas com aspectos da gravidez e das mudanças fisiológicas do corpo. 
A04 "[...] você caia no mundo das drogas e pode prejudicar o bebê."

A11 "[...] quando tiver problemas com sua família não vá buscar a "felicidade" nas drogas elas matam! [...] essa dependência das drogas começa as vezes por causa da TPM [...]"

A15“[...] Muitas vezes entrando no mundo do tráfico e ser morta ou presa."

A partir da fala de A4, a insatisfação com a gravidez não planejada ou precoce, leva o adolescente a iniciar o uso de drogas, principalmente por que a mídia e a sociedade em geral julgam a gravidez na adolescência e tratam-na como um problema social, o que gera uma série de conflitos emocionais, medo e insegurança nas gestantes. Segundo Silveira (2010), as pressões sociais acabam impedindo o apoio que as adolescentes grávidas necessitam.

A fala de A11 reforça o que Silva (2011) afirmou em seu trabalho ao constatar que o uso de drogas está diretamente ligado e influenciado por fatores biológicos, sociais, políticos e econômicos. Além disso, as causas são muitas vezes relacionadas a problemas e desajustes familiares.

\section{CONSIDERAÇOES FINAIS}

O presente trabalho, oriundo de uma ação didática sobre sexualidade, buscou relatar como as atividades foram desenvolvidas, e quais os resultados identificados a partir dessa experiência. Assim, na primeira atividade desenvolvida com os alunos, muitos relacionaram a sexualidade ao sexo, porém, a partir das discussões realizadas na roda da conversa, foi possível perceber que os alunos expressaram conceitos mais maduros em relação à sexualidade, uma vez que seus discursos envolviam sentimentos, respeito mútuo, valores. Entretanto, na análise das produções textuais, estiveram presentes, ainda que em poucos textos, os órgãos genitais, gravidez, ato sexual, drogas.

No conjunto das atividades, percebemos que os alunos ainda não apresentam uma ideia formada sobre o que é sexualidade e que estão cercados de muitos tabus e incertezas, o que pode ser o reflexo das influências da mídia e da sociedade na qual estão inseridos. No entanto, nos alunos que relacionaram a sexualidade com valores e atitudes verificamos que aos poucos, os adolescentes estão refletindo mais sobre essa questão, estão problematizando seus conceitos e olhando com mais respeito e responsabilidade para a busca pela identidade, pelo descobrir o próprio corpo, 
apaixonar-se, envolver-se e estão aceitando e procurando entender as mudanças pelas quais estão passando diariamente.

Diante das análises realizadas, verificamos que um trabalho com pequena carga horária, como o nosso, não é o suficiente para propor aos alunos atividades efetivas sobre sexualidade. No entanto, elas possibilitaram a sensibilização para determinados conceitos, que são pouco explorados ao tratar da temática sexualidade. Assim, sugerimos que as atividades desenvolvidas nas escolas sobre sexualidade sejam avaliadas, uma vez que, os alunos envolvidos nesse trabalho já haviam participado de outros momentos de discussão, mas que ainda apresentavam dúvidas e medo sobre o tema. Além disso, reforçamos que assuntos como esse sejam trabalhados de maneira longitudinal pelas diferentes disciplinas escolares e não apenas em ações pontuais.

\section{REFERÊNCIAS}

ALBINO, G. C.; VITALLE, M. S. de S; SCHUSSEL, E. Y.; BATISTA, N. A. A sexualidade pelo olhar das jovens: contribuições para a prática do médico de adolescentes. Rev. Paul. Pediatria, v. 23, p. 124-129, 2005.

AMORIM, R. M.; MAIA, A. C. B. Sexualidade na adolescência: dúvidas de alunos de uma escola pública. Revista Ibero-Americana de Estudos em Educação, v.07, n. 04, p. 95-106, 2012.

BRASIL. Ministério da Saúde. Adolescentes e Jovens para a educação entre os pares - Saúde e Prevenção nas escolas. Brasília, DF, 2010. Disponível em:

<http://bvsms.saude.gov.br/bvs/publicacoes/sexualidade_saude_reprodutiva.pdf.> Acesso em: 15 nov. 2014.

BORGES, A. L. V.; SCHOR, N. Início da vida sexual na adolescência e relações de gênero: um estudo transversal em São Paulo, Brasil, 2002. Cad. Saúde Pública, v. 21, n. 2, p. 499-507, 2005.

BRÊTAS, J. R .da S.; OHARA, C. V. da S.; JARDIM, D. P.; AGUIAR JUNIOR, W. de; OLIVEIRA, J. R. de. Aspectos da sexualidade na adolescência. Ciência \& Saúde Coletiva, v.17, p. 3221-3228, 2011.

CANO, M.A.T.; FERRIANI, M.G.C. Sexualidade na adolescência: um estudo bibliográfico. Rev. Latino Am. Enfermagem, v. 8, n. 2, p. 18-24, 2000.

CANO, M. A. T.; FERRIANI, M. G. C.; MEDEIROS, M.; GOMES, R. Auto-imagem na adolescência. Revista Eletrônica de Enfermagem, v.1, n.1, 1999.

CARDOSO, G. M.; LAZZAROTTO, E. M.; VAEZ, S. C.; GRUBHOFER, K.

Comportamento sexual: uma questão cultural. $1^{\mathrm{a}}$ ed. Cascavel:Coluna do saber, 2005. 
DAVIM, R. M. B.; GERMANO, R. M.; MENEZES, R. M. V.; CARLOS, D. J. D. Adolescente/adolescência: revisão teórica sobre uma fase crítica da vida. Revista Rene,v.10, n. 2, p.131-140, 2009.

FIGUEIRÓ, M. N. D. Educação sexual: como ensinar no espaço da escola. Revista Linhas, v.07, n.01, p. 1-21, 2006.

FOSSA, A. M. Educação sexual na escola: Um estudo junto a adolescentes. 2003, 189f. Dissertação (Programa de Pós-Graduação em Educação da UNIMEP) Faculdade de Ciências Humanas - Universidade Metodista de Piracicaba. Piracicaba, 2003.

GOMES, W. de A.; COSTA, M. C. O.; SOBRINHO, C. L. N.; SANTOS, C. A. de S. T.; BACELAR, E. B. Nível de informação sobre adolescência, puberdade e sexualidade entre adolescentes. Jornal da Pediatria, v. 78, n.04, p. 301-308, 2002.

GRIZZE, D. B; SANTOS, F. F. dos; OLIVEIRA, P. Sexualidade em discursos de alunos do Ensino Fundamental do Recife. Disponível em:

<http://www.ufpe.br/ce/images/Graduacao_pedagogia/pdf/2010.1/sexualidade\%20em\% 20discursos\%20de\%20alunos\%20do\%20ensino\%20fundamental\%20do.pdf> Acesso em: 27 jul.2014.

MARQUINI, M. de L. Atividades de sexualidade na escola para o aperfeiçoamento da cidadania dos alunos: limites e possibilidades.Disponível em:

$<$ http://www.gestaoescolar.diaadia.pr.gov.br/arquivos/File/producoes_pde/artigo_maria _lourdes_marquini.pdf> Acesso em: 27 jul. 2014.

MORAIS, M de F. A utilização de métodos participativos no ensino de engenharia de produção: o caso do curso de engenharia de produção agroindustrial da fecilcam. In: IV Encontro de produção científica e tecnológica, 2009, Campo Mourão. Anais..., Campo Mourão: FECILCAM/NUPEM, 2009.

PARANÁ. Sexualidade. Secretaria de Estado da Educação. Superintendência de Educação. Departamento de Diversidades. Núcleo de Gênero e Diversidade Sexual. Curitiba: SEED - PR, 2009. 216p.

PRADO, J. D. B. do; PAES, C. C.; FÍRBIDA, F. B. Gravidez na adolescência. Revista Catarse, v. 1, n. 2, p. 211-222, 2013.

RODRIGUEZ, N. G. M. Sexualidade: uma discussão com pais, alunos e professores da $7^{\mathrm{a}}$ série da escola Albert Einstein de Jaciara sobre o Tema Transversal Sexualidade.

Revista científica eletrônica de ciências sociais aplicadas da EDUVALE, Ano III, n. 05, p. 1-12, 2010.

SILVA, M. R. da. Causas do uso de drogas por adolescentes do bairro São Benedito no município de Formosa - GO. 2011, 25f. Monografia (Consórcio Setentrional de Educação a distância, curso de licenciatura em Biologia) - Universidade Estadual de Goiás, Brasília, 2011.

SILVA, S. C. da; PRATES, L. A.; SCARTON, J.; BARRETO, C. N.; ALVES, C. N.; WILHELM, L. A.; RESSEL, L. B. Mitos e dúvidas de adolescentes acerca das modificações corporais e suas implicações na sexualidade. Revista de Enfermagem da UFSM, v. 4, n. 2, p. 459-469, 2014. 
SILVEIRA, A. T. M. Gravidez na Adolescência: Um fenômeno complexo. 2010. 22 f. Trabalho de conclusão de curso (Especialização em atenção básica em saúde da família) - Universidade Federal de Minas Gerais, Uberaba, 2010.

SOUSA, L. B. de; FERNANDES, J. F. P.; BARROSO, M. G. T. Sexualidade na adolescência: análise da influência de fatores culturais presentes no contexto familiar. ACTA Paulista de Enfermagem, v.19, n.4, p. 408-413, 2006.

SOUZA, E de.; BALDWIN, J. R.; ROSA, F. H da. A. Construção sexual dos papéis sexuais femininos. Psicologia: Reflexão e crítica, v. 13, n. 03, p. 485-496, 2000.

TAQUETTE, S. R.;VILHENA, M. M. de. Uma contribuição ao entendimento da iniciação sexual feminina na adolescência. Psicologia em Estudo, v. 13, n. 1, p. 105$114,2008$. 